\title{
Optimized dosing regimen of hydroxychloroquine for treatment of coronavirus disease 2019 using Monte Carlo simulation
}

Sumit Leevanichchakhul ${ }^{1}$, Pitchaya Dilokpattanamongkol', Taniya Paiboonvong 2 , Suwida Tangtrakultham ${ }^{1}$, Supatat Chumnumwat ${ }^{1}$, Sasisopin Kiertiburanakul ${ }^{3}$, Preecha Montakantikul ${ }^{*}$

\author{
1 Department of Pharmacy, Faculty of Pharmacy, Mahidol University, Bangkok, Thailand \\ Department of Pharmacy Practice, College of Pharmacy, Rangsit University, Pathum Thani, Thailand \\ Department of Medicine, Faculty of Medicine Ramathibodi Hospital, Mahidol University, Bangkok, Thailand
}

\begin{abstract}
Optimized dosage regimens of hydroxychloroquine (HCQ) in coronavirus disease 2019 (COVID-19) are currently unknown. We aimed to determine regimens that rapidly achieved the pharmacokinetic-pharmacodynamic (PKPD) target for virological clearance in COVID-19 patients. Plasma HCQ concentration was simulated using a non-steady state, 2-compartment linear model. The plasma trough concentration $\left(C_{\text {trough }}\right) \geq 0.7 \mathrm{mg} / \mathrm{L}$ was used as the PKPD target. The loading dose of $800 \mathrm{mg}$ three times daily and 1,200 $\mathrm{mg}$ twice daily achieved the target on the first day with the probability of target attainment (PTA) $97.53 \%$ and $82.63 \%$, respectively. Maintenance dose of $200 \mathrm{mg}$ three times daily and $400 \mathrm{mg}$ twice daily provided PTA $>80 \%$ from day 3 through day 10 after the initiation of HCQ therapy. All proposed regimens had the PTA $<1 \%$ to achieve toxic level of $4 \mathrm{mg} / \mathrm{L}$. The optimal dose regimens for early viral clearance in COVID-19 patients were HCQ $800 \mathrm{mg}$ three times daily on the first day followed by $200 \mathrm{mg}$ three times daily for 9 days, and HCQ 1,200 mg twice daily on the first day followed by $400 \mathrm{mg}$ twice daily for 9 days. Further clinical study is needed to ensure clinical efficacy and safety of these regimens.
\end{abstract}

\section{Keywords:}

Coronavirus; COVID-19; Hydroxychloroquine; Monte Carlo simulation; SARS-CoV-2

\section{INTRODUCTION}

Coronavirus disease 2019 (COVID-19) is an outbreak of acute respiratory illness caused by severe acute respiratory syndrome coronavirus 2 (SARS-CoV-2). Fourteen percent of patients developed severe illness requiring oxygen therapy and approximately $5 \%$ have multi-organ dysfunction requiring intensive care unit (ICU) treatment ${ }^{1}$. Multiple host factors were associated with severity including age $\geq 50$ years, male sex, cardiovascular disease, diabetes, and malignancy ${ }^{2}$. However, there have not been any medications or other therapeutic options presently approved by the U.S. Food and Drug Administration (FDA) ${ }^{3}$. Hydroxychloroquine (HCQ) is currently being distributed to selected hospitals by the government in several countries, based on in vitro data and clinical studies showing potential benefits ${ }^{4-6}$. HCQ effectively inhibits viral replication by elevating the $\mathrm{pH}$ of endosomes and lysosomes ${ }^{7}$. Their anti-inflammatory properties that were demonstrated in the treatment of autoimmune diseases, may also reduce the inflammatory response to viral infection ${ }^{8}$.

Currently, there is no conclusive evidence to support the optimal dosing and duration of HCQ for the treatment of COVID-19. Several HCQ regimens have been proposed in in vitro studies including $400 \mathrm{mg}$ twice daily followed by $200 \mathrm{mg}$ daily for 4 days ${ }^{7}$. In Thailand, the current national guideline recommended the regimen of $600 \mathrm{mg}$ twice daily on the first day followed by $400 \mathrm{mg}$ daily for 4-9 days ${ }^{6}$. However, these regimens have not been

\section{*Corresponding author:}

*Preecha Montakantikul preecha.mon@mahidol.ac.th 
evaluated in the clinical study ${ }^{6,7}$.

In a small, open-label, non-randomized clinical trial (RCT) conducted in mild COVID-19 patients using HCQ $200 \mathrm{mg}$ three times daily showed the negative results for SARS-CoV-2 RNA by polymerase chain reaction (PCR) from the nasopharyngeal swab, indicating the virological clearance was achieved within 3-6 days of the treatment ${ }^{9}$. In contrast, the same dose of HCQ did not show virological clearance during 5-6 days of the treatment in an observational study because most patients had significant comorbidities associated with poor outcomes ${ }^{10}$. A pilot study with the dose of HCQ $400 \mathrm{mg}$ daily for 5 days found no difference in the rate of virological clearance at day 7 compared with placebo $^{11}$. Also, in another open-label, RCT with the regimen of loading dose HCQ 1,200 mg daily for three days followed by a maintenance dose of $800 \mathrm{mg}$ daily for 3-4 weeks showed no significant increase in the virological clearance rate at day 28 when compared with routine standard of care without $\mathrm{HCQ}^{12}$.

Because of the conflicting results reported from the different dosing regimens of HCQ, the study to determine optimal HCQ dosing regimen that achieves favourable efficacy and less toxicity is needed. Monte Carlo simulation is a mathematical technique that randomly generates drug concentration based on a pharmacokinetic (PK) model and probability distribution of PK parameters. It is used for calculation of the probability of target attainment (PTA), which is the possibility of the selected dose regimens to achieve the pharmacokinetic-pharmacodynamic (PKPD) target ${ }^{13,14}$. Based on in vitro SARS-CoV-2 viral load inhibition by $\mathrm{HCQ}^{7}$, a rapid increase in HCQ concentration should theoretically result in an early decline in viral load and possibly increase rate of virological clearance. Thus, this study aimed to determine the optimal HCQ regimens that rapidly attained the PKPD target for virological clearance in COVID-19 patients, together with the possibility to achieve the toxic level.

\section{MATERIALS AND METHODS}

\subsection{Pharmacokinetic model}

Based on short-term treatment of HCQ in COVID-19, we employed a non-steady state PK data derived from a two-compartment linear model with first-order absorption and lag time from healthy subjects and malaria patients for simulation ${ }^{15}$. The population PK parameters used in this study are shown in Table 1. In addition, oral bioavailability (F) of HCQ was fixed to 0.746 referred from the previous study ${ }^{16}$.

\subsection{Pharmacodynamic model}

PKPD target associated with virological clearance was found only in the open-label, non-RCT conducted in mild COVID-19 patients. At day 6 of treatment, patients receiving HCQ with negative PCR for SARSCoV-2 RNA from nasopharyngeal swab had a mean serum HCQ concentration of $0.612 \mathrm{mg} / \mathrm{L}^{9}$. However, the patients with significant comorbidities associated with poor outcomes receiving the same dose of HCQ did not show virological clearance with mean trough concentration of $0.678 \mathrm{mg} / \mathrm{L}^{10}$. Besides, the study of HCQ determination in systemic lupus erythematosus patients found that the serum concentration of HCQ is higher than plasma concentration with ratio of 0.54:0.44 ${ }^{17}$. Therefore, we considered plasma trough concentration $\left(\mathrm{C}_{\text {trough }}\right)$ of $0.7 \mathrm{mg} / \mathrm{L}$ at any day of treatment as the minimum PKPD target for virological clearance. The simulated plasma maximum concentration $\left(\mathrm{C}_{\max }\right)$ of the lowest reported toxicity after a single dose ingestion of $4 \mathrm{~g} \mathrm{HCQ}$, was used as a cut-off level for toxicity ${ }^{18}$.

\subsection{Monte Carlo simulation}

The mean values of PK parameter and interindividual variability (IIV) from the final population PK model were used to simulate HCQ plasma concentration of 10,000 subjects during day 1-10 using Monte Carlo simulation (Crystal Ball 2017 v.2.2; Decisioneering Inc., Denver, CO). There were 8 regimens chosen from in vitro study, clinical studies, Thai national guideline, along with our proposed regimens, were simulated (Table 2). Regimens with high loading doses were expected to rapidly achieve the PKPD target. Lognormal distributions were set for between-patient variability. PTA was calculated as the percentage of all 10,000 estimates which achieve the target plasma $C_{\text {trough }}$ $\geq 0.7 \mathrm{mg} / \mathrm{L}$. Regimen yielding PTA of $>90 \%$ is considered optimal ${ }^{13}$. PTA of the toxic level was also calculated to assure the safety of simulated regimens.

\section{RESULTS}

The simulated plasma HCQ concentrations of different regimens are shown in Figure 1. There were six regimens (regimen $3,4,5,6,7$, and 8 ) that could reach the target plasma $\mathrm{C}_{\text {trough }}$ of $0.7 \mathrm{mg} / \mathrm{L}$ within 10 days of therapy. However, only two regimens (regimen 7 and 8) could reach the target since day 1 .

The PTA analyses of various HCQ regimens are shown in Table 3. For published regimens, regimen 1 and 2 could not achieve PTA target of $C_{\text {trough }} \geq 0.7 \mathrm{mg} / \mathrm{L}$; but regimens 3, 4, and 5 achieved $90 \%$ PTA on day 10 , 7 , and 7 , respectively.

For our proposed regimens, regimen 6 achieved $90 \%$ PTA of $C_{\text {trough }} \geq 0.7 \mathrm{mg} / \mathrm{L}$ on day 6 . Loading dose of $800 \mathrm{mg}$ three times daily on the first day in regimen 7 provided PTA of $97.53 \%$, while $1,200 \mathrm{mg}$ twice daily on the first day in regimen 8 provided PTA of $82.63 \%$. 
Maintenance dose of regimen 7 , and 8 provided PTA $>80 \%$ from day 3 through day 10 after the initiation of HCQ therapy.

Simulated $\mathrm{C}_{\max }$ from a single toxic dose of $4 \mathrm{~g}$ was $4 \mathrm{mg} / \mathrm{L}$. Once daily dosing in regimen 5 attained $>$ $1 \%$ PTA of $\mathrm{C}_{\max } \geq 4 \mathrm{mg} / \mathrm{L}$ since day 7 , but all other regimens had the PTA $<1 \%$ over 10-day course of HCQ therapy. Increasing frequency to three times daily in regimen 7 increased the PTA of $\mathrm{C}_{\text {trough }} \geq 0.7 \mathrm{mg} / \mathrm{L}$, reduced the PTA of $\mathrm{C}_{\max } \geq 4 \mathrm{mg} / \mathrm{L}$, and help reduce total maintenance dose per day.

Table 1. Estimate population pharmacokinetic parameters ${ }^{15}$.

\begin{tabular}{cllll}
\hline Parameters & Units & Estimate value & \multicolumn{1}{c}{ IIV } & \multicolumn{1}{c}{ SD* } \\
\hline $\mathrm{k}_{\mathrm{a}}$ & $\mathrm{hr}^{-1}$ & 1.15 & N/A (fixed at 0) & N/A (fixed at 0) \\
$\mathrm{ALAG}$ & $\mathrm{hr}$ & 0.3890 & 0.036 & 0.074 \\
$\mathrm{Vc}$ & $\mathrm{L}$ & 437 & 0.232 & 210.487 \\
$\mathrm{Vp}$ & $\mathrm{L}$ & 1,390 & 0.715 & 1175.352 \\
$\mathrm{Q}$ & $\mathrm{L} / \mathrm{hr}$ & 45.1 & N/A (fixed at 0) & N/A (fixed at 0) \\
$\mathrm{CL} / \mathrm{F}$ & $\mathrm{L} / \mathrm{hr}$ & 10.9 & 0.161 & 4.374 \\
\hline
\end{tabular}

*Standard deviation $=$ Estimate value $\times \sqrt{I I V}$

$\mathrm{IIV}=$ interindividual variability, $\mathrm{k}_{\mathrm{a}}=$ absorption rate constant, $\mathrm{ALAG}=$ absorption lag time, $\mathrm{Vc}=$ central volume of distribution, $\mathrm{Vp}=$ peripheral volume of distribution, $\mathrm{Q}=$ intercompartmental clearance, $\mathrm{CL} / \mathrm{F}=$ apparent clearance

Table 2. Hydroxychloroquine dosage regimens for simulations.

\section{Dose regimens}

$400 \mathrm{mg}$ OD for 5 days

$400 \mathrm{mg}$ BID day 1 , then $200 \mathrm{mg}$ BID for 4 days

$200 \mathrm{mg}$ TID for 10 days

$600 \mathrm{mg}$ BID day 1 , then $400 \mathrm{mg}$ BID for 9 days

$1,200 \mathrm{mg}$ OD day $1-3$, then $800 \mathrm{mg}$ OD for 3-4 weeks

$800 \mathrm{mg}$ BID day 1 , then $400 \mathrm{mg}$ BID for 9 days

$800 \mathrm{mg}$ TID day 1 , then $200 \mathrm{mg}$ TID for 9 days

$1,200 \mathrm{mg}$ BID day 1 , then $400 \mathrm{mg}$ BID for 9 days

$\mathrm{OD}=$ once daily, $\mathrm{BID}=$ twice daily, $\mathrm{TID}=$ three times daily

Table 3. Probability of target attainment for different hydroxychloroquine regimens with targets of $\mathrm{C}_{\text {trough }} \geq 0.7 \mathrm{mg} / \mathrm{L}$ for virological clearance in COVID-19 and $\mathrm{C}_{\max } \geq 4 \mathrm{mg} / \mathrm{L}$ for toxic level.

\begin{tabular}{|c|c|c|c|c|c|c|c|c|c|c|}
\hline \%PTA & D1 & D2 & D3 & D4 & D5 & D6 & D7 & D8 & D9 & D10 \\
\hline \multicolumn{11}{|l|}{400 mg OD D1 - D5 } \\
\hline $\mathrm{C}_{\text {trough }} \geq 0.7 \mathrm{mg} / \mathrm{L}$ & 0.00 & 0.14 & 1.77 & 6.40 & 13.42 & 5.81 & 2.43 & 1.02 & 0.40 & 0.23 \\
\hline $\mathrm{C}_{\max } \geq 4 \mathrm{mg} / \mathrm{L}$ & 0.00 & 0.00 & 0.00 & 0.00 & 0.00 & 0.00 & 0.00 & 0.00 & 0.00 & 0.00 \\
\hline \multicolumn{11}{|c|}{$400 \mathrm{mg}$ BID D1 then $200 \mathrm{mg}$ BID D2 - D5 } \\
\hline $\mathrm{C}_{\text {trough }} \geq 0.7 \mathrm{mg} / \mathrm{L}$ & 0.95 & 4.32 & 11.46 & 20.25 & 29.33 & 15.00 & 7.51 & 3.95 & 1.77 & 0.98 \\
\hline $\mathrm{C}_{\max } \geq 4 \mathrm{mg} / \mathrm{L}$ & 0.00 & 0.00 & 0.00 & 0.00 & 0.00 & 0.00 & 0.00 & 0.00 & 0.00 & 0.00 \\
\hline \multicolumn{11}{|c|}{$200 \mathrm{mg}$ TID D1 - D10 } \\
\hline $\mathrm{C}_{\text {trough }} \geq 0.7 \mathrm{mg} / \mathrm{L}$ & 0.13 & 7.44 & 27.54 & 48.20 & 63.77 & 73.97 & 81.27 & 85.97 & 89.48 & 91.49 \\
\hline $\mathrm{C}_{\max } \geq 4 \mathrm{mg} / \mathrm{L}$ & 0.00 & 0.00 & 0.00 & 0.00 & 0.00 & 0.00 & 0.01 & 0.01 & 0.01 & 0.01 \\
\hline \multicolumn{11}{|c|}{$600 \mathrm{mg}$ BID D1 then $400 \mathrm{mg}$ BID D2 - D10 } \\
\hline $\mathrm{C}_{\text {trough }} \geq 0.7 \mathrm{mg} / \mathrm{L}$ & 10.12 & 36.68 & 60.99 & 75.72 & 84.65 & 89.58 & 92.76 & 94.88 & 96.26 & 97.24 \\
\hline $\mathrm{C}_{\max } \geq 4 \mathrm{mg} / \mathrm{L}$ & 0.00 & 0.00 & 0.01 & 0.01 & 0.02 & 0.05 & 0.11 & 0.20 & 0.43 & 0.66 \\
\hline \multicolumn{11}{|c|}{$1,200 \mathrm{mg}$ OD D1-3 then $800 \mathrm{mg}$ OD D4 - D10 } \\
\hline $\mathrm{C}_{\text {trough }} \geq 0.7 \mathrm{mg} / \mathrm{L}$ & 6.07 & 45.43 & 73.04 & 80.38 & 86.19 & 89.73 & 92.40 & 94.17 & 95.29 & 96.23 \\
\hline $\mathrm{C}_{\max } \geq 4 \mathrm{mg} / \mathrm{L}$ & 0.02 & 0.29 & 1.06 & 0.46 & 0.65 & 0.86 & 1.38 & 1.74 & 2.30 & 2.89 \\
\hline \multicolumn{11}{|c|}{$800 \mathrm{mg}$ BID D1 then $400 \mathrm{mg}$ BID D2 - D10 } \\
\hline $\mathrm{C}_{\text {trough }} \geq 0.7 \mathrm{mg} / \mathrm{L}$ & 32.46 & 52.20 & 70.26 & 81.35 & 87.53 & 91.25 & 93.83 & 95.43 & 96.59 & 97.40 \\
\hline $\mathrm{C}_{\max } \geq 4 \mathrm{mg} / \mathrm{L}$ & 0.00 & 0.00 & 0.00 & 0.01 & 0.08 & 0.15 & 0.21 & 0.29 & 0.45 & 0.81 \\
\hline \multicolumn{11}{|c|}{$800 \mathrm{mg}$ TID D1 then $200 \mathrm{mg}$ TID D2 - D10 } \\
\hline $\mathrm{C}_{\text {trough }} \geq 0.7 \mathrm{mg} / \mathrm{L}$ & 97.53 & 74.06 & 79.84 & 84.86 & 88.61 & 91.25 & 93.15 & 94.67 & 95.68 & 96.57 \\
\hline $\mathrm{C}_{\max } \geq 4 \mathrm{mg} / \mathrm{L}$ & 0.10 & 0.01 & 0.01 & 0.01 & 0.02 & 0.03 & 0.06 & 0.07 & 0.08 & 0.09 \\
\hline \multicolumn{11}{|c|}{ 1,200 mg BID D1 then $400 \mathrm{mg}$ BID D2 - D10 } \\
\hline $\mathrm{C}_{\text {trough }} \geq 0.7 \mathrm{mg} / \mathrm{L}$ & 82.63 & 74.27 & 82.73 & 88.12 & 91.77 & 94.15 & 95.69 & 96.76 & 97.48 & 98.00 \\
\hline $\mathrm{C}_{\max } \geq 4 \mathrm{mg} / \mathrm{L}$ & 0.41 & 0.04 & 0.07 & 0.11 & 0.17 & 0.24 & 0.41 & 0.64 & 0.90 & 0.98 \\
\hline
\end{tabular}

PTA $=$ probability of target attainment, $\mathrm{OD}=$ once daily, $\mathrm{BID}=$ twice daily, $\mathrm{TID}=$ three times daily, $\mathrm{C}_{\text {trough }}=$ trough concentration, $\mathrm{C}_{\max }=$ maximum concentration 


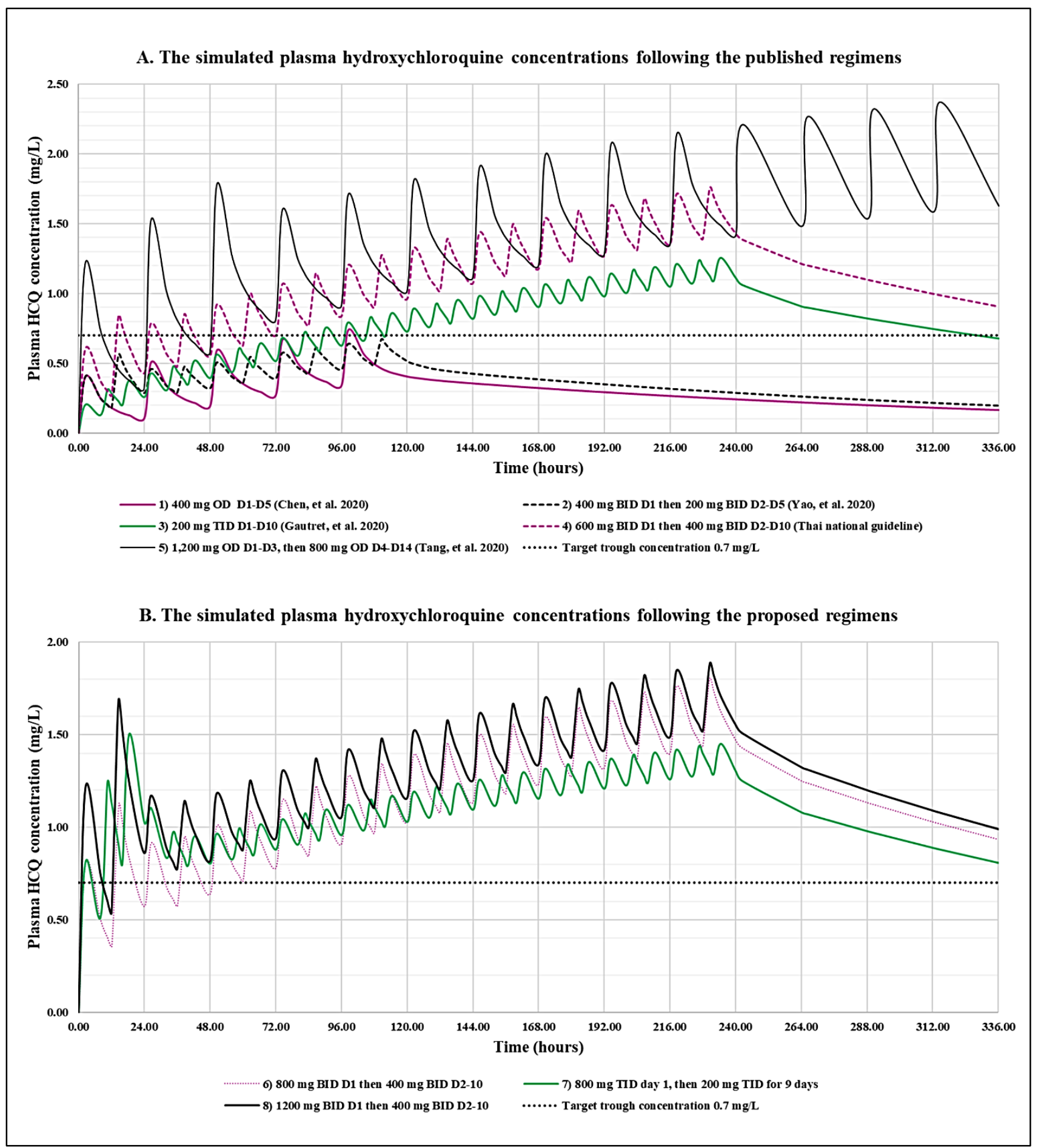

Figure 1. The simulated plasma hydroxychloroquine concentrations of different regimens. A. following the regimens in in vitro study, clinical studies, and Thai national guideline. None of the regimens were achieved target $C_{\text {trough }} \geq 0.7 \mathrm{mg} / \mathrm{L}$ on day 1 . B. following the proposed regimens, regimen 7 and 8 could achieve target $C_{\text {trough }} \geq 0.7 \mathrm{mg} / \mathrm{L}$ on day 1 , and maintain $C_{\text {trough }} \geq 0.7 \mathrm{mg} / \mathrm{L}$ over 14 day with 10 -day course of therapy; $\mathrm{OD}=$ once daily, $\mathrm{BID}=$ twice daily, $\mathrm{TID}=$ three times daily, $\mathrm{D}=$ day

\section{DISCUSSION}

The simulation of HCQ concentration at infected lung tissue is the ideal method for determine the dosage in COVID-19. Despite concentration in lung epithelial lining fluid of HCQ $400 \mathrm{mg}$ once daily or 200 $\mathrm{mg}$ three times daily is higher than the maximum EC50 seen in critically ill COVID-19 patients $^{19}$, the absence of correlation with clinical outcome and heterogeneity of EC50 values through modelling techniques are limited the dosage determination. Therefore, we use plasma concentration that correlate with virological clearance as PKPD target.

The incapability to achieve the PKPD target of $400 \mathrm{mg}$ daily for 5 days (regimen 1) with the maximum PTA of $13.42 \%$ on day 5 in our simulation was consistent 
with the absence of increasing virological clearance rate in the study of mild COVID-19 patients, whereas patients' baseline characteristics were comparable between placebo and hydroxychloroquine groups ${ }^{11}$. Similarly, loading dose of HCQ $400 \mathrm{mg}$ twice daily on the first day followed by $200 \mathrm{mg}$ twice daily for 4 days (regimen 2) was insufficient in our simulation (maximum PTA of $29.33 \%$ on day 5). This regimen was proposed by using physiologically-based pharmacokinetic models that reached the target free lung trough concentration over half maximal effective concentration $\left(\mathrm{EC}_{50}\right)$, however the validity was limited due to animal pharmacokinetics data and in vitro target ${ }^{7}$. HCQ $200 \mathrm{mg}$ three times daily (regimen 3) showed delayed achievement of PTA (91.49\% PTA on day 10). Although virological clearance defined by negative results of SARS-CoV-2 RNA PCR from the nasopharyngeal swab was shown on day 3-6 of therapy in the study of mild COVID-19 patients using regimen 3, the PCR was still positive up to day 6 of therapy in the patients using the same regimen who had older age (mean age; 45.1 vs 58.7 years old) and cancer ${ }^{9,10}$. In addition, Thai national guideline recommends the loading dose of HCQ $600 \mathrm{mg}$ twice daily on the first day followed by $400 \mathrm{mg}$ twice daily for 9 days (regimen 4$)^{6}$, however this regimen showed delayed achievement of PTA (92.76\% PTA on day 7). The virological clearance outcome of regimen 4 has not yet been evaluated in the clinical study. Even the loading dose of HCQ 1,200 mg once daily for three days followed by $800 \mathrm{mg}$ once daily (regimen 5) could achieve $92.4 \%$ PTA on day 7 in our simulation. This regimen showed no increase in virological clearance rate in mild to moderate COVID-19 patients as compared with the standard of care alone, however, the absence of HCQ benefit from delayed treatment cannot be excluded ${ }^{12}$.

Some host factors were related to prolonged viral shedding and severity including male sex, and cancer ${ }^{2}$, 20-22. The specific mechanism of differences in duration of infections and risk for complication is unclear. Female sex hormones could suppress the SAR-CoV replication and decrease accumulation of inflammatory monocyte macrophages in the lung of female mice ${ }^{23}$. Immunosuppressive state is possibly the cause of delayed viral clearance in cancer patients ${ }^{24}$. While the host factors related to poor outcome cannot be modified, we were able to optimize HCQ regimens that could maximize the viral load reduction. Moreover, higher levels of cytokine storm indicated by increased levels of proinflammatory cytokines including interleukin (IL)2, IL-4, IL-6, IL-10, along with tumor necrosis factor (TNF)- $\alpha$ and interferon (IFN)- $\gamma$ were associated with more severe disease development in COVID-19 patients. Among several proinflammatory cytokines, IL-6 and IL-10 were rapidly increase in more severe group ${ }^{25}$. IL-6 contributes to host defence against infections; however, excessive synthesis of IL-6 leads to an acute severe systemic inflammatory response. HCQ had the dosedependent reduction of T helper 17 cell-related IL-6 production in autoimmune patients, whereas $\mathrm{IFN}-\alpha$ reduction was limited in long term HCQ use for 6 months ${ }^{26,27}$. Therefore, there was a possibility that early increase of HCQ concentration might be benefit by timely reducing overproduction of IL-6 in COVID-19 patients.

Thus, we proposed the HCQ dose regimens of $1,200 \mathrm{mg}$ twice daily on the first day followed by $400 \mathrm{mg}$ twice daily for 9 days (regimen 7) and $800 \mathrm{mg}$ three times daily on the first day followed by $200 \mathrm{mg}$ three times daily for 9 days (regimen 8). These two regimens could achieve the target plasma $C_{\text {trough }} \geq 0.7 \mathrm{mg} / \mathrm{L}$ for virological clearance since the first day and thereafter, over 10-day course of HCQ therapy. This is the first study that proposed the high loading dose $2,400 \mathrm{mg}$ in the first day, but each dosage was not exceeded the regimen in published clinical study ${ }^{12}$. Our results were supported by PK properties. HCQ has long plasma half-life (32 \pm 9 days $)^{16}$, therefore, steady-state plasma concentration cannot be achieved within the treatment course of COVID-19, if the adequate loading dose is not given. In addition, the loading dose should be high enough to compete with the large volume of HCQ distribution $(1,390 \mathrm{~L})$ to the peripheral compartments ${ }^{15}$, and to rapidly achieve the target $\mathrm{C}_{\text {trough }}$ in the central compartment. Also, to overcome the large distribution of HCQ to peripheral compartment, increasing dosage frequency is needed to maintain $\mathrm{C}_{\text {trough }}$ in the central compartment above the target throughout the duration of treatment ${ }^{28}$. For these reasons, our proposed regimen that the loading dose was increased to 2,400 $\mathrm{mg}$ per day together with the frequency of 8-hour interval (regimen 7) was the optimal regimen as shown in the PTA analysis (Table 3 ), while regimen 8 , with 12 -hour dosing interval was optional for settings with restricted access to COVID-19 patients.

In the context of safety, we also evaluated the probabilities to achieve the toxic level by using simulated $\mathrm{C}_{\max }$ of $4 \mathrm{mg} / \mathrm{L}$, which all our proposed regimens (regimen 6-8) provided PTA less than $1 \%$ over a 10-day course of HCQ therapy. Maximum concentrationrelated gastrointestinal (GI) adverse events (AEs) might be a concern when our regimen is chosen ${ }^{29}$, therefore decreased peak concentration by split-dosing during the treatment course should be applied to reduce the GI AEs. Conversely, retinal toxicity was identified in patients taking HCQ for greater than 5 years ${ }^{30}$, this AE would less likely occur during a short period for COVID-19 treatment ${ }^{12}$.

The most concerned AEs of HCQ is the QTc prolongation, however the relationship between HCQ concentration and QTc prolongation is currently unknown. The inhibition of the inward rectifier $\mathrm{K}+$ channels is likely to be associated with QTc prolonga- 
tion but the half-maximal inhibitory concentration (IC50) of HCQ was not reported in in vitro study ${ }^{31}$. In a PK study of 13 critically ill COVID-19 patients, two patients had to discontinue HCQ due to QTc prolongation and they had HCQ whole blood concentration of 0.03 $\mathrm{g} / \mathrm{L}$ and $1.74 \mathrm{mg} / \mathrm{L}$. Risk factors associated with QTc prolongation were not reported in this study, but QTc prolongation from critical illness cannot be excluded ${ }^{32}$. Furthermore, the randomized controlled trial of hospitalized COVID-19 patients received HCQ 2,000 mg in the first day ( $800 \mathrm{mg}$ every 6 hours for 2 doses then $400 \mathrm{mg}$ at 12 hours after the initial dose) followed by $400 \mathrm{mg}$ twice daily for 9 days did not show any excess in ventricular tachycardia or ventricular fibrillation compared with usual care ${ }^{33}$.

Many risk factors contributing to QTc prolongation have been reported, including female sex, structural heart diseases, electrolyte disturbances, hepatic/renal failure, baseline QTc > 450 milliseconds, concomitant QTc prolonging medications and ICU status at the time of treatment ${ }^{34,35}$. Due to limited data of high dose HCQ usage in patients with risk factor of QT prolongation, our regimens may not be recommended in patients with risk factor of QT prolongation, or balancing risk and benefit before use has to be considered.

Centers for Disease Control and Prevention (CDC) and National institute of health (NIH) are not recommended hydroxychloroquine for treating COVID-19 based on recent clinical studies that showed no additional benefit on mortality reduction or

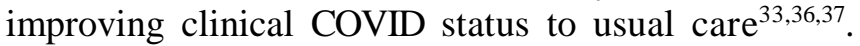
However, underdosing lead to a potential lack of benefit cannot be exclude. Even the highest dose in randomized controlled trial, HCQ2,000 mg in first day $(800 \mathrm{mg}$ every 6 hours for 2 doses then $400 \mathrm{mg}$ at 12 hours after the initial dose) followed by $400 \mathrm{mg}$ twice daily for 9 days showed delayed achievement of PTA in our simulation. Therefore, we proposed dose regimens to further investigate in clinical studies, principally the plasma concentration-effect relationship.

Our study has some limitations. First, we simulated the plasma HCQ concentration using population PK parameters derived from both healthy and malaria-infected patients, which may be altered in severe COVID-19 patients. For example, GI absorption was decreased due to shunting of blood to vital organs, distribution was increased due to inflammation state, and elimination was decreased in hepatic or renal failure patients $^{38}$. Second, we used plasma concentration that achieves virological clearance in nasopharyngeal swab as PKPD target, which may not be completely correlated with clinical improvement in COVID-19 patients. However, it is generally accepted that viral clearance in nasopharyngeal swab is a desirable marker for clinical improvement and transmission prevention ${ }^{39}$.

\section{CONCLUSIONS}

The two optimal HCQ regimens that may help for early viral clearance in COVID-19 patients were HCQ $800 \mathrm{mg}$ three times daily on the first day followed by $200 \mathrm{mg}$ three times daily for 9 days, and HCQ 1,200 $\mathrm{mg}$ twice daily on the first day followed by $400 \mathrm{mg}$ twice daily for 9 days. Further clinical study is needed to ensure efficacy and safety of these regimens.

\section{ACKNOWLEDGEMENT}

We would like to thank Phinnaphit Saengpao for her help throughout the study. My sincere thanks also go to my beloved mother and wife for their encouragement throughout the research period.

\section{Conflict of interest}

The authors declared no competing interest for this work.

\section{Funding}

This study received no external funding.

\section{Ethics approval}

This study was approved by the Institutional Review Board of Faculty of Dentistry/Faculty of Pharmacy, Mahidol University (COE.No.MU-DT/PY-IRB 2020/ 014.2005).

\section{Article info:}

Received January 42021

Received in revised form April 27, 2021

Accepted May 13, 2021

\section{Authors' contributions}

PM, SL conceived and designed the study. SL, TP, ST performed the research. PM, SL analysed and interpreted the data. SL, PD wrote the manuscript. PM, SK, PD, SC revised manuscript and all of the authors approved the final manuscript.

\section{REFERENCES}

1. Wu Z, McGoogan JM. Characteristics of and important lessons from the coronavirus disease 2019 (COVID-19) outbreak in China: summary of a report of 72314 cases from the Chinese center for disease control and prevention. JAMA. 2020;323(13):1239-42.

2. Shi Y, Yu X, Zhao H, Wang H, Zhao R, Sheng J. Host susceptibility to severe COVID-19 and establishment of a host risk score: findings of 487 cases outside Wuhan. Crit Care. 2020;24(1):108.

3. Centers for Disease Control and Prevention. COVID-19 science update. [document on the internet]; 2020 [cited 2021 April 20]. Available from: http://www.cdc.gov/library/covid19.

4. Government of India Ministry of Health and Family Welfare Directorate General of Health Services. Clinical management protocol: COVID-19. [document on the internet]; 2020 [cited 2021 April 20]. Available from: https://www.mohfw.gov.in/pdf/Clinical ManagementProtocolforCOVID19.pdf.

5. United Arab Emirates Ministry of Health and Prevention. National guidelines for clinical management and treatment of 
COVID-19. [document on the internet]; 2020 [cited 2021 April 20]. Available from: https://services.dha.gov.ae/sheryan/wps/ portal/home/circular-details?circularRefNo=CIR-2020-000001 $68 \&$ isPublic ircular $=1 \&$ fromHome $=$ true.

6. Thai Department of Medical Services. Treatment guidelines for COVID-19. [document on the internet]; 2020 [cited 2021 April 20]. Available from: https://covid19.dms.go.th/Content/Select_ Landding_page? contentId $=69$.

7. Yao X, Ye F, Zhang M, Cui C, Huang B, Niu P, et al. In vitro antiviral activity and projection of optimized dosing design of hydroxychloroquine for the treatment of severe acute respiratory syndrome coronavirus 2 (SARS-CoV-2). Clin Infect Dis. 2020;71(15):732-9.

8. Schrezenmeier E, Dorner T. Mechanisms of action of hydroxychloroquine and chloroquine: implications for rheumatology. Nat Rev Rheumatol. 2020;16(3):155-66.

9. Gautret P, Lagier JC, Parola P, Hoang VT, Meddeb L, Mailhe $\mathrm{M}$, et al. Hydroxychloroquine and azithromycin as a treatment of COVID-19: results of an open-label non-randomized clinical trial. Int J Antimicrob Agents. 2020;56(1):105949.

10. Molina JM, Delaugerre C, Le Goff J, Mela-Lima B, Ponscarme $\mathrm{D}$, Goldwirt L, et al. No evidence of rapid antiviral clearance or clinical benefit with the combination of hydroxychloroquine and azithromycin in patients with severe COVID-19 infection. Med Mal Infect. 2020;50(4):384.

11. Chen J, Liu D, Liu L, Liu P, Xu Q, Xia L, et al. A pilot study of hydroxychloroquine in treatment of patients with moderate COVID-19. Zhejiang Da Xue Xue Bao Yi Xue Ban. 2020;49(2): 215-9.

12. Tang W, Cao Z, Han M, Wang Z, Chen J, Sun W, et al. Hydroxychloroquine in patients with mainly mild to moderate coronavirus disease 2019: open label, randomised controlled trial. BMJ. 2020;369:m1849.

13. Bradley JS, Dudley MN, Drusano GL. Predicting efficacy of antiinfectives with pharmacodynamics and Monte Carlo simulation. Pediatr Infect Dis J. 2003;22(11):982-95.

14. Roberts JA, Kirkpatrick CM, Lipman J. Monte Carlo simulations: maximizing antibiotic pharmacokinetic data to optimize clinical practice for critically ill patients. J Antimicrob Chemother. 2011;66(2):227-31.

15. Lim HS, Im JS, Cho JY, Bae KS, Klein TA, Yeom JS, et al. Pharmacokinetics of hydroxychloroquine and its clinical implications in chemoprophylaxis against malaria caused by Plasmodium vivax. Antimicrob Agents Chemother. 2009;53(4): 1468-75

16. Tett SE, Cutler DJ, Day RO, Brown KF. Bioavailability of hydroxychloroquine tablets in healthy volunteers. Br J Clin Pharmacol. 1989;27(6):771-9.

17. Carlsson H, Hjorton K, Abujrais S, Rönnblom L, Åkerfeldt T, Kultima K. Measurement of hydroxychloroquine in blood from SLE patients using LC-HRMS-evaluation of whole blood, plasma, and serum as sample matrices. Arthritis Res Ther. 2020;22(1):125.

18. Miller D, Fiechtner J. Hydroxychloroquine overdosage. J Rheumatol. 1989;16(1):142-3.

19. Ruiz S, Concordet D, Lanot T, Georges B, Goudy P, Baklouti $S$, et al. Hydroxychloroquine lung pharmacokinetics in critically ill patients with COVID-19. Int J Antimicrob Agents. 2021;57(2):106247.

20. Xu K, Chen Y, Yuan J, Yi P, Ding C, Wu W, et al. Factors associated with prolonged viral RNA shedding in patients with COVID-19. Clin Infect Dis. 2020;71(15):799-806.

21. Ogimi C, Greninger AL, Waghmare AA, Kuypers JM, Shean $\mathrm{RC}, \mathrm{Xie} \mathrm{H}$, et al. Prolonged shedding of human coronavirus in hematopoietic cell transplant recipients: risk factors and viral genome evolution. J Infect Dis. 2017;216(2):203-9.

22. Zhang L, Zhu F, Xie L, Wang C, Wang J, Chen R, et al. Clinical characteristics of COVID-19-infected cancer patients: a retrospective case study in three hospitals within Wuhan, China.
Ann Oncol. 2020;31(7):894-901.

23. Channappanavar R, Fett C, Mack M, Ten Eyck PP, Meyerholz DK, Perlman S. Sex-based differences in susceptibility to severe acute respiratory syndrome coronavirus Infection. J Immunol. 2017;198(10):4046-53.

24. Hijano DR, Maron G, Hayden RT. Respiratory viral infections in patients with cancer or undergoing hematopoietic cell transplant. Front Microbiol. 2018;9:3097.

25. Han H, Ma Q, Li C, Liu R, Zhao L, Wang W, et al. Profiling serum cytokines in COVID-19 patients reveals IL-6 and IL-10 are disease severity predictors. Emerg Microbes Infect. 2020; 9(1):1123-30.

26. Silva JC, Mariz HA, Rocha LF Jr, Oliveira PS, Dantas AT, Duarte AL, et al. Hydroxychloroquine decreases Th17-related cytokines in systemic lupus erythematosus and rheumatoid arthritis patients. Clinics (Sao Paulo). 2013;68(6):766-71.

27. Willis R, Seif AM, McGwin G Jr, Martinez-Martinez LA, González EB, Dang N, et al. Effect of hydroxychloroquine treatment on pro-inflammatory cytokines and disease activity in SLE patients: data from LUMINA (LXXV), a multiethnic US cohort. Lupus. 2012;21(8):830-5.

28. Rosenbaum SE. Basic pharmacokinetics and pharmacodynamics: an integrated textbook and computer simulations. $2^{\text {nd }}$ ed. Hoboken: NJ: John Wiley \& Sons; 2017.

29. Munster T, Gibbs JP, Shen D, Baethge BA, Botstein GR, Caldwell J, et al. Hydroxychloroquine concentration-response relationships in patients with rheumatoid arthritis. Arthritis Rheum. 2002;46(6):1460-9.

30. Yusuf IH, Sharma S, Luqmani R, Downes SM. Hydroxychloroquine retinopathy. Eye (Lond). 2017;31(6):828-45.

31. Traebert M, Dumotier B, Meister L, Hoffmann P, DominguezEstevez M, Suter W. Inhibition of hERG K+ currents by antimalarial drugs in stably transfected HEK293 cells. Eur J Pharmacol. 2004;484(1):41-8.

32. Perinel S, Launay M, Botelho-Nevers E, Diconne É, LoufDurier A, Lachand R, et al. Towards optimization of hydroxychloroquine dosing in intensive care unit COVID-19 patients. Clin Infect Dis. 2020;71(16):2227-9.

33. The recovery collaborative group. Effect of hydroxychloroquine in hospitalized patients with COVID-19. N Engl J Med. 2020;383(21):2030-40.

34. Mercuro NJ, Yen CF, Shim DJ, Maher TR, McCoy CM, Zimetbaum PJ, et al. Risk of QT interval prolongation associated with use of hydroxychloroquine with or without concomitant azithromycin among hospitalized patients testing positive for coronavirus disease 2019 (COVID-19). JAMA Cardiol. 2020;5(9):1036-41.

35. Tisdale JE, Jaynes HA, Kingery JR, Mourad NA, Trujillo TN, Overholser BR, et al. Development and validation of a risk score to predict QT interval prolongation in hospitalized patients. Circ Cardiovasc Qual Outcomes. 2013;6(4):479-87.

36. WHO solidarity trial consortium. Repurposed antiviral drugs for COVID-19 - Interim WHO solidarity trial results. N Engl J Med. 2021;384(6):497-511.

37. The National Institutes of Health. Antiviral drugs that are approved or under evaluation for the treatment of COVID-19. [document on the internet]; 2020 [cited 2021 April 20]. Available from: https://www.covid19treatmentguidelines.nih. gov/antiviral-therapy.

38. Smith BS, Yogaratnam D, Levasseur-Franklin KE, Forni A, Fong J. Introduction to drug pharmacokinetics in the critically ill patient. Chest. 2012; 141(5):1327-36.

39. Centers for Disease Control and Prevention. Discontinuation of transmission-based precautions and disposition of patients with COVID-19 in healthcare settings. [document on the internet]; 2020 [cited 2021 April 20]. Available from: https:// www.cdc.gov/coronavirus/2019-ncov/hcp/disposition-hospitalized-patients.html. 